\title{
MULHER ACOMETIDA PELO PAPILOMAVÍRUS HUMANO E REPERCUSSÕES NA FAMÍLIA
}

\author{
Attacked woman by human papillomavirus \\ and repercussions in the family \\ La mujere afectada por el virus del papiloma humano \\ y las repercusiones para la familia
}

Ana Karina Bezerra Pinheiro²

\section{RESUMO}

0 objetivo foi avaliar a estrutura, o desenvolvimento e o funcionamento da família composta por mulher acometida pelo Papilomavírus Humano, com base no Modelo Calgary. Foi realizado um estudo de caso no domicílio da participante por meio de entrevista semiestruturada com o casal, genograma e ecomapa da família. Em exame ginecológico, foram diagnosticadas na participante do estudo uma verruga externa e uma pequena lesão na junção escamocolunar do colo uterino. A esposa compartilhou o caso com o marido, culpando-o, mas posteriormente conseguiu conscientizá-lo da importância dos hábitos sexuais seguros. 0 casal conseguiu superar a fase crítica vivenciada, deixando como repercussão a mudança de hábitos e maior afeição familiar. Com relação ao tema estudado, verifica-se que muitas pessoas ainda o desconhecem, ficando a cargo dos profissionais de saúde difundirem 0 assunto. Assim como também promover a educação em saúde para que as pessoas reflitam a respeito da importância de utilizar o preservativo.

Palavras-chave: Avaliação. Família. Doenças Virais Sexualmente Transmissíveis. Enfermagem.

\begin{abstract}
The aim was to evaluate the structure, the development and the function of the family composed by attacked woman by Human Papillomavirus, based in the Calgary Model. It Was realized one case study at the home of the informer through interview semistructured with the couple, genogram and echomap of the family. By gynecological exam it was diagnosed in partnership of study, one external wart and one small lesion in the scalecolumnar junction of the uterus colon. The housewife shared the case with her husband, accusing him, but lately she got acquired him of the importance from safe sexual habits. The couple got over comes the grasped critical phases, overlooking as repercussion, the changing of their habits and bigger affection on the family. Regarding the theme studied, it was observed that many people still doesn't know it, making the health professionals responsible to spread the subject. As well as to promote the education within health, in order to make the people think about and reflect the great importance in utilizing the prophylactic.
\end{abstract}

Keywords: Evaluation. Family. Sexually transmissible viral diseases. Nursing.

\section{Resumen}

El objetivo fue evaluar la estructura, el desarrollo y el funcionamiento de la familia compuesta por mujeres afectadas por el vírus del papiloma humano, con base en el Modelo Calgary. Se realizó un estudio de caso en el domicilio de las participantes a través de una entrevista semiestructurada con la pareja, genograma y ecomapa de la familia. Durante el examen ginecológico realizado en una participante del estudio, fue diagnosticado una verruga externa y una pequeña lesión en la unión escamo-colunar del cuello uterino. La esposa atribuyó la culpa al marido, pero después consiguió concientizarlo de la importancia de los hábitos sexuales seguros. La pareja superó la fase crítica, cambiando los hábitos y viviendo en un entorno familiar más afectuoso. . Con respecto al tema estudiado, parece que mucha gente todavía desconoce el tema, se verifica que muchas personas lo desconocen todavía; por lo que son los profesionales de la salud que tienen que difundir ell asunto y promover la educación de la salud, además de permitir que las personas reflexionen sobre la importancia de utilizar el condón o preservativo..

Palabras clave: Evaluación. Familia. Enfermedades virales de transmisión sexual. Enfermería.

\footnotetext{
${ }^{1}$ Enfermeira. Mestre em Enfermagem pela Universidade Federal do Ceará. Brasil. E-mail: mirellajoca@hotmail.com, ${ }^{2}$ Enfermeira. Doutora em Enfermagem. Professora Adjunta II da UFC. Brasil. E-mail: anakarinaufc@hotmail.com
} 
Mulher acometida pelo papilomavírus humano Joca MT, Pinheiro AKB

\section{INTRODUÇÃO}

Família pode ser definida de várias formas; neste estudo, foi adotada a definição de família quem seus membros dizem que são, ou seja, quem a família considera como família. ${ }^{1}$ Resolveu-se realizar o estudo com esta definição em virtude das mudanças que vêm ocorrendo na estrutura tradicional das famílias.

Toda família tem momentos de alegria e momentos de crises, dentre estes está o surgimento de uma doença. Todos os dias, várias pessoas são acometidas por algum tipo de doença, e essas pessoas em sua maioria fazem parte de um contexto familiar. As políticas públicas de saúde têm como prioridade as doenças sexualmente transmissíveis (DST), pois são consideradas problemas relevantes devido à repercussão no processo saúde-doença e nas altas taxas de mortalidade que podem causar.

O papilomavírus humano (HPV) é uma doença infecciosa, frequentemente transmitida por via sexual, podendo ser também por meio de roupa íntima contaminada ou assentos sanitários; conhecida como condiloma acuminado, verruga genital ou crista de galo. ${ }^{2}$

Em 2001 cerca de $9 \%$ a 13\% da população estava infectada com o HPV. Esse vírus é o principal agente causal do câncer de colo do útero. As taxas de incidência de infecção para - HPV alcançam cerca de $30 \%$ a $40 \%$ em pacientes abaixo dos 20 anos, e, após os 35 anos de idade, essa prevalência diminui para cerca de 10\%. Enquanto a infecção pelo HPV diminui com a idade, a incidência do câncer cervical aumenta, sugerindo que a prevalência da infecção pelo HPV é necessária para produzir lesões de alto grau. ${ }^{3}$

0 câncer de colo do útero é considerado o segundo mais comum entre mulheres brasileiras. 0 número de casos novos de câncer de colo uterino esperados para o Brasil em 2008 é de 18.680; no Nordeste, estimam-se 4.720 casos novos, e, em Alagoas, estimam-se 270 novos casos 4 .

Nas mulheres, mais de $65 \%$ das infecções regridem espontaneamente, de acordo com a imunidade, e 14\% progridem para lesões displásicas. ${ }^{5} \mathrm{~A}$ doença caracteriza-se pela recorrência elevada; até $45 \%$ dos doentes tratados podem manter o vírus latente, que pode ficar instalado no organismo por um longo período sem se manifestar, entrando em ação em determinadas situações que ocorrem a baixa da imunidade. ${ }^{6}$

0 despertar pelos estudos, por parte das pesquisadoras desta pesquisa, na área saúde sexual e reprodutiva, ocorreu em decorrência da preocupação com a saúde pública, dos questionamentos e anseios das mulheres com relação ao HPV; por isso, resolveu-se realizar o aprofundamento neste tema, para que se pudesse melhor compreender os sentimentos e experiências das mulheres acometidas por esse vírus.

Como estas mulheres fazem parte de um contexto social, surgiu a intenção de pesquisá-la em seu meio familiar, pois a participação e o apoio da família são tão importantes quanto a pessoa-índice para o melhor prognóstico da doença. A família precisa ser ouvida e compreendida nas suas necessidades e dificuldades. ${ }^{7} 0$ apoio dispensado pelos familiares é importante para que haja o bom desenvolvimento de qualquer acometimento. A família funciona como suporte social de apoio de extrema relevância, é considerada como um vínculo de união. ${ }^{8}$

Com isso, deu-se início aos questionamentos: será que a manifestação de uma DST, fato que muitas vezes os familiares desconhecem, causa impactos na família? De que forma essa doença pode causar possíveis influências na estrutura, na dinâmica ou na função familiar? A qual fator a família associa o acometimento desta doença?

Para que o trabalho pudesse ser mais bem desenvolvido, utilizou-se como suporte teórico o Modelo Calgary de Avaliação da Família (MCAF); com ele, elabora-se a capacidade de conhecer e avaliar a estrutura, o desenvolvimento e 0 funcionamento de qualquer que seja a família, proporcionando então um meio eficiente de conhecê-la no seu modo de viver e experienciar o processo saúde-doença.

Então, torna-se relevante o aprofundamento nessa temática, por haver a possibilidade de conhecer algumas das possíveis causas de crises e abalos no seio familiar, podendo assim esclarecer os achados, proporcionando a diminuição das ameaças na unidade familiar, pois é por meio dos estudos e das descobertas que podemos solucionar ou amenizar diversos problemas.

\section{OBJETIVOS}

GERAL

- Observar a estrutura, o desenvolvimento e 0 funcionamento da família composta por mulher acometida pelo HPV, com base no Modelo Calgary.

\section{ESPECÍFICOS}

- Conhecer influências no desenvolvimento e funcionamento da família, em decorrência da doença;

- Interpretar fatores os quais a mulher relaciona com a causa da doença.

\section{PERCURSO METODOLÓGICO}

0 estudo teve abordagem qualitativa por favorecer a avaliação da estrutura, do desenvolvimento e do funcionamento da família, utilizando como referencial teórico o MCAF, proposto por Wright e Leahey (2002). A pesquisa qualitativa aponta que os conhecimentos sobre os indivíduos somente são possíveis com a descrição da experiência humana, tal como ela é vivida e definida por seus próprios atores. ${ }^{9}$

A pesquisa foi do tipo descritiva; a finalidade desses estudos é observar, descrever e documentar os aspectos da situação, procurando assim conhecer e interpretar a realidade sem nela interferir para modificá-la. ${ }^{10}$

0 MCAF proporciona uma estrutura que facilita 0 entendimento do funcionamento das famílias de modo 
interacional, proporciona avaliar as famílias em sua totalidade. Para delinear as estruturas da família assim como também o contexto sugere-se a utilização de dois instrumentos: 0 genograma e o ecomapa. 0 genograma é um diagrama do grupo familiar e o ecomapa é um diagrama do contato da família com outras pessoas. ${ }^{1}$ Esses dois instrumentos de pesquisa serão mais bem visualizados posteriormente com as Figuras 1 e 2 , respectivamente.

Foi realizado um estudo de caso, juntamente com uma família em que a mulher fora acometida pelo HPV. 0 estudo de caso ilumina a compreensão do leitor sobre o fenômeno estudado, pode revelar a descober ta de novos significados, ampliar a experiência do leitor ou confirmar o já conhecido. ${ }^{11}$

A pesquisa foi realizada inicialmente em um consultório médico de Maceió, capital de Alagoas, que foi escolhido em razão da acessibilidade de uma das pesquisadoras; houve a escolha intencional da pessoa-índice do estudo, por meio do acesso aos prontuários. Os critérios para seleção da participante do estudo foram: ter sido acometida pelo HPV em qualquer fase da sua vida; ter uma família constituída; ter mais de 18 anos de idade; ter sido diagnosticada e tratada no consultório particular selecionado; aceitar participar do estudo.

Após essa seleção, foi estabelecido um contato com ela no consultório médico; neste encontro, houve a apresentação da pesquisadora e o esclarecimento da realização da pesquisa, depois foi feito o convite para a colaboração na pesquisa. Com 0 aceite, solicitou-se que a mesma assinasse o termo de consentimento. Ainda neste primeiro contato, foi agendado 0 próximo encontro, uma visita domiciliária.

Amostragem intencional baseia-se no pressuposto de que o conhecimento do pesquisador sobre a população pode ser usado para selecionar o caso a ser estudado. 0 pesquisador pode selecionar propositalmente ou escolher o sujeito que irá participar da pesquisa. ${ }^{9}$ Visita domiciliária é um dos instrumentos mais indicados para começar a trabalhar 0 indivíduo, a família e a comunidade, sendo assim um conjunto de ações de saúde voltadas para o atendimento, tanto educativo como assistencial; por meio dela podemos avaliar as condições ambientais e físicas em que vivem o indivíduo e sua família. ${ }^{12}$

Quando a visita à mulher acometida pelo HPV foi realizada, aproveitou-se o momento para convidar o esposo dela para também participar da pesquisa, em virtude da íntima relação da doença com o casal e não somente com um indivíduo. Com o aceite dele em colaborar com o estudo, solicitou-se também a assinatura do termo de consentimento.

Foram realizados quatro encontros com a família, três deles com a mulher acometida pelo HPV, pessoa-índice da pesquisa, e o outro encontro com o esposo dela. Com estes encontros ficaram esclarecidos os dados necessários para 0 desenvolvimento da pesquisa; contudo, ficou acordado com a família que poderia ser necessário marcar um novo encontro, caso houvesse necessidade no decorrer da análise dos dados.

A coleta de dados foi realizada em janeiro e fevereiro de 2007, foram coletados alguns dados do prontuário da mulher acometida pelo vírus, assim como por meio de entrevista semiestruturada com o uso de um gravador, para que posteriormente facilitasse a transcrição das falas. A entrevista foi constituída de tópicos norteadores que abordavam os três aspectos do MCAF. 0 genograma e o ecomapa da família foram estruturados de acordo com os dados coletados.

Na entrevista semiestruturada, o entrevistador utiliza um guia de tópicos para garantir que todas as pretensões sejam alcançadas, bem como surgem outros questionamentos advindos do desenvolvimento da própria entrevista. ${ }^{9}$

Os dados foram apresentados de acordo com as falas pertinentes do casal, e foram identificados pontos relevantes para serem subdivididos com base no Modelo Teórico, nas categorias: avaliação estrutural, avaliação de desenvolvimento e avaliação funcional. Posteriormente, estabeleceu-se a conexão entre os temas família, HPV e o Modelo Calgary, para assim realizar os apontamentos do estudo.

Os princípios éticos da pesquisa que envolve seres humanos foram respeitados, de acordo com a Resolução n 196/96. 0 projeto foi enviado ao Comitê de Ética em Pesquisa da Universidade Federal do Ceará para apreciação, obtendo a aprovação em janeiro de 2007, de acordo com o protocolo 03/07.

0 casal foi informado de que os dados da pesquisa seriam divulgados com fins científicos, porém sempre preservando as identidades; para isso, foram utilizados nomes fictícios, que foram escolhidos de forma aleatória.

\section{APRESENTAÇÃO E DISCUSSÃO DOS RESULTADOS}

\section{Avaliação Estrutural}

Ao avaliar uma família é preciso examinar sua estrutura, quem faz parte dela, o vínculo afetivo entre seus membros comparados com os indivíduos de fora e qual é o seu contexto. ${ }^{1}$

A família estudada era constituída por Josué, 37 anos de idade, provedor do lar, empresário e excessivamente envolvido com o trabalho; por Rosa, pessoa-índice da pesquisa, 30 anos de idade, administradora; por Gabriel, 12 anos de idade, que estava cursando o $8^{\circ}$ ano; e por Bela, 6 anos de idade, que estava cursando $02^{\circ}$ ano. Esta família possuía boa base educacional e um nível socioeconômico favorecido.

Os dois instrumentos propostos pelo MCAF foram utilizados para avaliar a estrutura da família em questão, para que ficasse melhor a visualização de todo o grupo familiar. A demonstração da família de Rosa e de Josué é elucidada no genograma, estando demarcada quem a informante do estudo considerou como família. Isto é possível visualizar na Figura 1: 
Figura 01 - Genograma

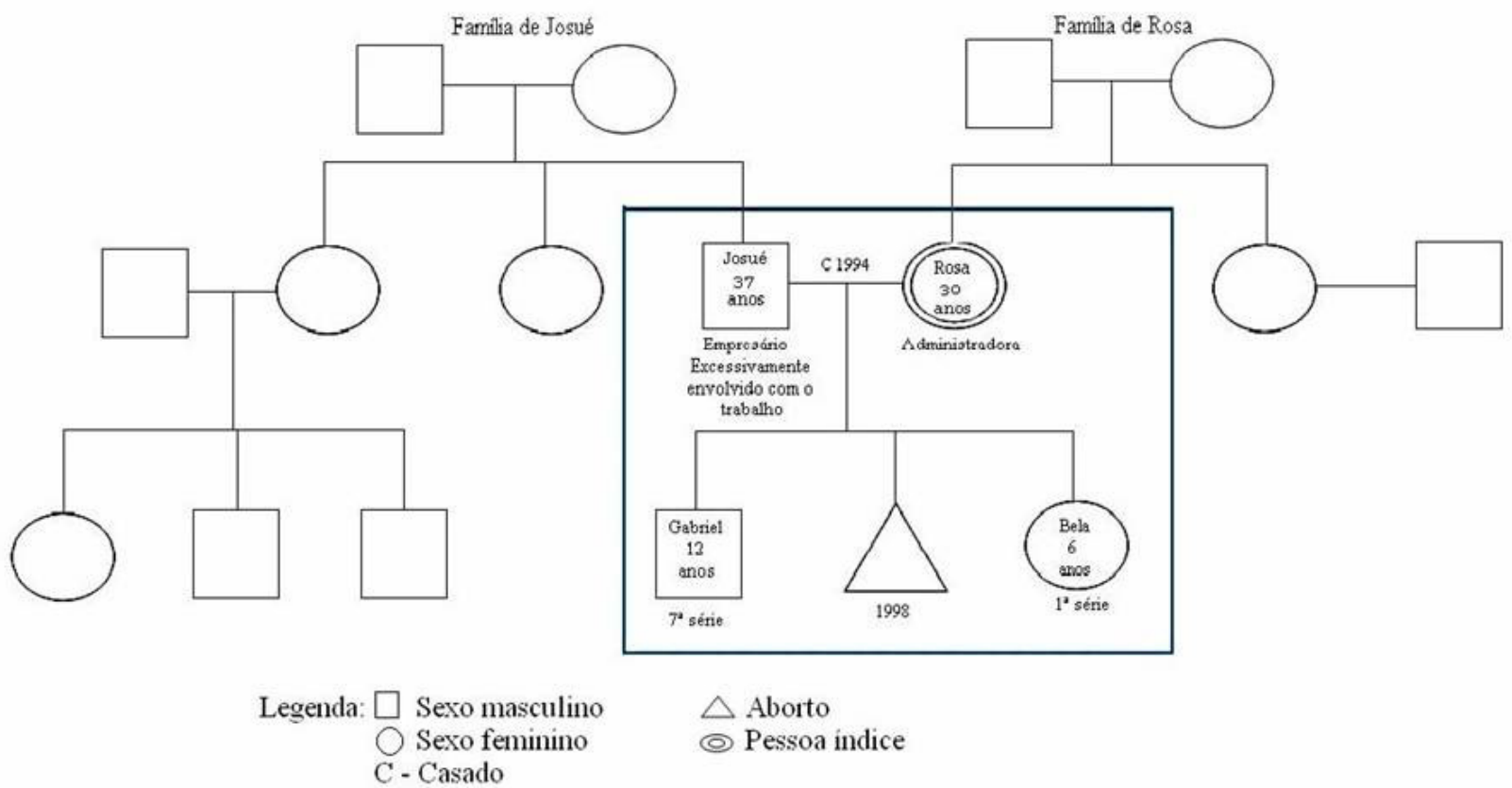

Ao serem avaliados os relacionamentos da família de Rosa com os sistemas mais amplos por meio do ecomapa, foi percebido que o contato deles com a família extensa era significativo. Essa família revelou vários relacionamentos, que podem ser úteis em caso de auxílio na solução de problemas, como é possível visualizar na Figura 2:

Figura 02 - Ecomapa da Familia de Rosa

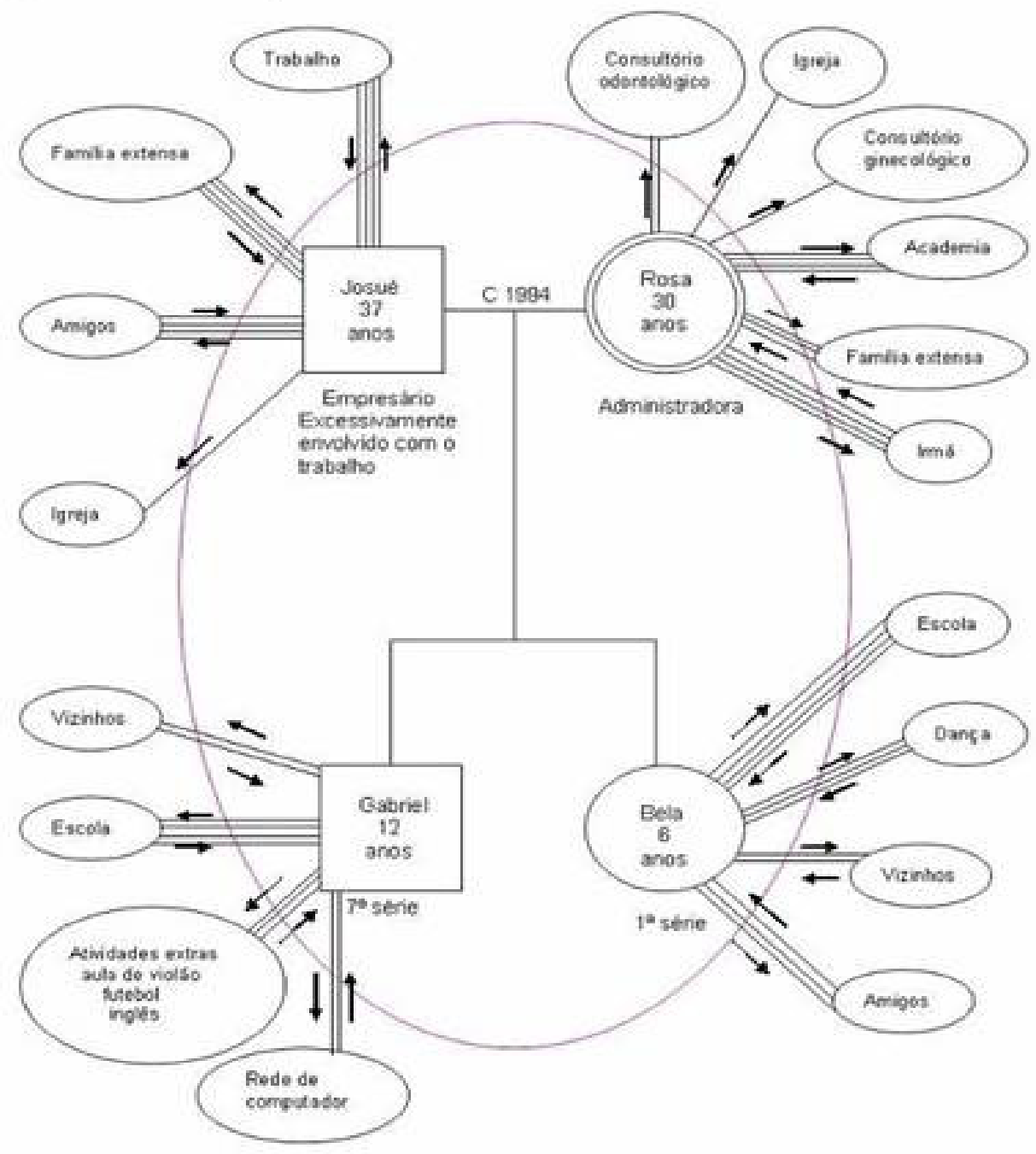

$$
\begin{aligned}
& \text { Legenda: - Vinculos Muito Superficiais } \equiv \text { Vinculos Moderados } \\
& \text { =Vinculos Superficiais } \quad \equiv \text { Vinculos Fortes }
\end{aligned}
$$


Quando indagados sobre a definição de família, Rosa e Josué relataram:

Eu acho que família tem o núcleo familiar, que é o cerne que convive junto, mora junto, que no meu caso é marido, eu e os dois filhos. Minha família somos nós quatro, aí tem família de maneira geral que é minha irmã, minha mãe, meu pai e tem as familias afins, que eu ganhei com o casamento, que é sogra, cunhados, cunhadas (Rosa).

Familia é algo sagrado, que deve durar para sempre (Josué).

A iniciação sexual precoce repercute nas relações familiares e faz com que os adolescentes se deparem com as DST, a gravidez e 0 aborto. ${ }^{13}$ Rosa participava desta realidade, pois teve início da vida sexual aos 15 anos com o seu atual marido, engravidou também precocemente, aos 16 anos de idade, e foi acometida pelo HPV; a suspeita do contágio por esse vírus iniciou aos 25 anos de idade.

A família não está assumindo seu papel de educadora em relação ao exercício de uma sexualidade saudável, seja por despreparo da família ou pela presença de tabus que interferem no processo educativo. ${ }^{13} \mathrm{~A}$ enfermagem vem tentando enfatizar a promoção de educação em saúde, bem como diagnosticar precocemente a infecção pelo HPV; contudo, normalmente as pessoas só procuram o serviço de saúde para o tratamento, e não para a prevenção.

\section{Avaliação de Desenvolvimento}

0 conceito de desenvolvimento da família é a trajetória exclusiva construída por uma família, modelada por eventos previsíveis e imprevisíveis, como: doença, catástrofes e tendências sociais. ${ }^{1}$

Para Rosa e Josué, a doença não foi causadora de uma crise, pois ela disse que já esperava por isso, por saber de todo o histórico dele. Para ela sempre há eventos os quais afetam 0 desenvolvimento da família, e a maioria desses eventos gera amadurecimento, o HPV foi um desses.

A mudança de comportamento de Josué, após vários diálogos, segundo Rosa, influenciou as crianças, pois ele passou a ser mais participativo com as atividades dos filhos; antes ele só queria ir para as orgias. Rosa não considerava o fato de ficar sabendo das traições de Josué como uma descoberta, porque para ela não era traição dele ter uma companheira fixa, mas saídas esporádicas. A infidelidade pode ser perturbadora e, consequentemente, a mais capaz de destruir a relação, que não seja necessariamente por causa do sexo, mas por causa do segredo e das mentiras que o envolvem. ${ }^{14}$

A descoberta do acometimento com o HPV aconteceu em uma consulta de rotina ao ginecologista; o assunto era desconhecido para o casal. Ao escutar o diagnóstico ela disse que não demonstrou nenhuma reação, e Josué disse que sentiu um sentimento de culpa e de profundo arrependimento pela transmissão do vírus.

0 sentimento de indiferença, diante do resultado, é atribuído a uma forma de desconhecimento da doença no momento do diagnóstico. Estatísticas revelam que $1 / 3 \mathrm{da}$ população feminina sexualmente ativa é portadora do HPV, mas a doença ainda é desconhecida entre a maioria das mulheres e da sociedade como um todo. ${ }^{14}$

Foi realizada uma cirurgia a laser para remoção da lesão na junção escamocolunar do colo uterino, era uma lesão única e pequena. Rosa apresentou também uma verruga isolada nos pequenos lábios, foi aplicado ácido tricloroacético uma única vez, e obteve-se a resposta esperada ao tratamento, a regressão da verruga. Após a realização do tratamento, Rosa ficou sendo acompanhada pelo ginecologista para que pudessem observar a reação do organismo; o médico afirmou que o vírus havia estabilizado e que não havia mais lesão, apenas uma pequena cicatriz.

Rosa tinha convicção de que adquiriu o vírus através da relação sexual com o próprio esposo, em consequência de relacionamentos extraconjugais dele, pois ele não tinha 0 costume de usar preservativo. Josué afirmou que para ele não tinha nenhum motivo justificante para a contaminação com o HPV, apenas a irresponsabilidade própria da idade.14

Para Rosa o que mais provocou em decorrência do acometimento com o HPV foi a questão da conscientização. As DSTs podem repercutir complicações no âmbito físico, emocional e social. 0 estigma dessas doenças ainda permanece ardente na sociedade, podendo ter muitas repercussões na sexualidade do indivíduo. ${ }^{13}$ Rosa demonstrava receio de que as pessoas pudessem prejulgá-los por ter adquirido uma DST.

Para Rosa, o fator pelo qual o indivíduo adquire HPV é a falta de cuidado no ato sexual; ela disse que seria impraticável usar preservativo durante todo o casamento; Josué também afirmou ser a falta de cuidado nas relações sexuais, porém disse não ter nenhum conhecimento formado sobre o tema, não sabia como era o vírus, nem como pegava, nem a forma de transmissão. Josué culpava-se por Rosa ter sido acometida pelo vírus, talvez pela forma como ela repassou para ele, culpando-o de tudo, ou até mesmo por saber dos comportamentos de risco que já teve.

Antes da descoberta do vírus, o casal já havia conversado com relação às condutas de Josué, pois Rosa já se sentia insatisfeita com as saídas do esposo, e quando se deparou com o acometimento, isso serviu para ela frisar ainda mais o modo de ele viver. Josué disse que houve um desgaste na relação de confiança sexual com a esposa.

Ainda se tratando das repercussões causadas pela contaminação com uma DST, especificamente na vida de Rosa, isso causou preocupação, pois ela disse que todo ano fazia o exame preventivo, para ter certeza que a lesão foi extinta, ficando um pouco tensa até receber o resultado; disse ainda que a pessoa fica um período encucada, mas que supera; 
Mulher acometida pelo papilomavírus humano Joca MT, Pinheiro AKB

segundo Josué, ele sentiu motivação para repensar valores sagrados como a família; ele disse que inicialmente afetou, mas que a esposa dele era uma pessoa maravilhosa e soube superar, mediante um trabalho de reconquista.

Rosa disse que conseguiu estabelecer um diálogo franco com Josué, e que não soube de mais nenhum ato poligâmico dele; disse ainda ter conseguido superar todos os momentos vividos.

\section{AVALIAÇÃO FUNCIONAL}

A avaliação funcional avalia o funcionamento da família, 0 comportamento entre seus membros. ${ }^{1}$

Quando Rosa ficou sabendo do acometimento com o HPV, segundo ela, Josué reagiu fechando-se nas profundezas dos seus pensamentos, silenciando. Já Josué interpretou a reação de sua esposa, como de decepção moral e tristeza, disse ainda que afetivamente ela ficou muito vulnerável, desconfiada de tudo, insegura.

Rosa em nenhum momento demonstrou que tinha medo; apesar de saber que o HPV é um grande precursor para o câncer cervical, ela sempre mostrava a possibilidade de cura e a importância do diálogo com o marido. Quando soube da doença, Rosa culpou seu marido, porém ele não a culpou. Ela justificava a acusação devido ao histórico sexual dele. A inculpação por haver adquirido a doença faz a pessoa repensar suas atitudes diante dos fatos, requer principalmente mudança de comportamento e um acordo entre os parceiros. ${ }^{14}$ Mesmo com todos os sentimentos de culpa, um apoiou o outro. 0 casal viu a doença como um problema superado, tratado fisicamente e superado psicologicamente.

Quando indagada sobre os impactos causados pelo HPV, Rosa afirmou que gerou algumas desconfianças, interrogações, mas que era o papel que a pessoa se sujeitava quando amava, contudo havia superado. Josué disse que causou um repensar na vida, valorização maior na família e no amor verdadeiro; para ele inicialmente o diagnóstico os afastou, mas somando a outros fatores sentimentais, sem qualquer correlação, posteriormente os aproximou. 0 diálogo familiar é fator primordial para a comunicação, possibilita superar incompreensões e dificuldades ocasionais. ${ }^{15}$

0 amor ajudou o casal a superar o problema vivenciado. É interessante quando o casal, que é acometido por uma DST, consegue estabelecer uma conversa leal, facilitando o tratamento e prevalecendo a continuação dos cuidados, sendo também relevante quando consegue alterar os costumes de risco para a saúde sexual de um ou de ambos os indivíduos, e superar a fase vivenciada, como foi o caso da família participante do estudo.
Esc Anna Nery Rev Enferm 2009 jul-set; 13 (3): 567-73

\section{CONSIDERAÇÕES FINAIS}

A temática deste estudo tornou a pesquisa bastante complexa, já que os assuntos são desafiadores para os profissionais de saúde; o assunto família ainda é bastante incipiente, e o modelo, pouco divulgado. Com isso, corroboro a relevância dos temas explanados no decorrer desta pesquisa.

As informações a respeito das DST, em particular do HPV, ainda ficam muito a desejar, partindo do princípio de que Rosa não tinha nenhum conhecimento sobre 0 assunto quando descobriu a doença, e Josué não tinha e continuava sem ter conhecimento sobre o tema, percebendo, assim, que houve 0 tratamento da lesão em Rosa, mas faltaram esclarecimentos sobre o tema para o casal.

Pelo diagnóstico de HPV estabelecido nessa família, particularmente em Rosa, e por ela e seu companheiro terem um bom nível socioeconômico, observou-se que o papilomavírus humano e a falta de informações sobre este vírus não atingem somente os níveis socioeconômicos menos favorecidos.

As repercussões que ficaram mais evidentes no casal, devido ao acometimento com o HPV, foi a conscientização dos hábitos, a desconfiança, a preocupação com a recidiva e a motivação para repensar na valia que possui uma família. É bastante identificável também a responsabilidade que Rosa atribuiu a Josué, o fato de terem sido acometidos por esse vírus, devido às atitudes sexuais de risco que o marido já havia vivenciado. Também é percebido com bastante veemência que Josué assumiu a culpa da doença e sempre enaltecia o valor da família.

Um grande fator observado no desenvolvimento da família foi que, após a mudança nos comportamentos de Josué, ele passou a ser mais presente e participativo dentro do lar, principalmente com as atividades dos filhos. E no funcionamento, foi a inculpação de Josué por Rosa, devido ao fato dele calar-se com os seus pensamentos e sentimentos de culpa.

0 fator mais pronunciado pelo casal, com relação à causa da doença, foi a falta de cuidados na hora do contato sexual; mesmo eles tendo pouco conhecimento a respeito do HPV, sabiam a conduta que o indivíduo deveria ter para evitar o acometimento com o vírus. Contudo, por conversas e provas de afetividade, o casal conseguiu superar o problema vivenciado.

Com este estudo pode-se mais uma vez confirmar a importância que a educação sexual tem; os profissionais de enfermagem não podem deixar passar despercebida a habilidade que possuem em repassar informações para a população, com a orientação individual, grupal ou em família. 0 enfermeiro deve estar em contínua atenção para visualizar possíveis causas de problemas, para que possa cuidar, além dos fatores consequentes de doença, os que podem prevenilas. 


\section{REFERÊNCIAS}

1. Wright LM, Leahey M. Enfermeiras e famílias: um guia para avaliação e intervenção na família. $3^{a}$ ed. São Paulo (SP): ROCA; 2002.

2. Ministério da Saúde (BR). Gestação de alto risco. 4ª ed. Brasília (DF); 2000.

3. Organização Mundial de Saúde-OMS A saúde no Brasil. [on-line] [citado 15 nov 2001. Disponível em: ftp://ftp.ufv.br/dns/ especializ_dns/disciplinas/politicas_de_saude_br.pdf.

4. Instituto Nacional de Câncer- INCA Incidência de câncer no Brasil. [citado 8 maio 2008] .Disponível em: www.inca.gov.br/estimativa/ 2008.

5. Instituto de Câncer do Ceará. Registro de câncer de base populacional: distribuição do total de casos de câncer matriculados no hospital, segundo localização topográfica e sexo. Fortaleza(CE); 2002

6. Carvalho GM. Enfermagem em ginecologia. São Paulo(SP): EPU; 2004.

7. Paes PFA, Espírito Santo FH. Limites e possibilidades no cotidiano do familiar que cuida do idoso com Alzheimer no ambiente domiciliar. Esc Anna Nery Rev Enferm 2005; 9 (2): 192-98.
8. Joca MT. Desempenho do papel de nutriz: interação familiar e suporte de apoio [trabalho de conclusão de curso]. Fortaleza (CE): Universidade Federal do Ceará; 2004

9. Polit DF, Hungler BP. Pesquisa e análise qualitativa. In: Polit DF, Hungler BP. Fundamentos de pesquisa em enfermagem métodos, avaliação e utilização. $3^{\text {a }}$ ed. Porto Alegre(RS): Artes Médicas; 1995.

10. Polit DF, Beck CT, Hungler BP. Fundamentos de pesquisa em enfermagem: métodos, avaliação e utilização. Tradução de Ana Thoreel. $5^{\text {a }}$ ed. Porto Alegre(RS): Artes Médicas; 2004.

11. André MEDA. Estudo de caso em pesquisa e avaliação educacional. Brasília (DF): Líber Livro Ed; 2005.

12. Kawamoto EE, Santos MCH, Mattos TM. Enfermagem comunitária. São Paulo (SP): EPU; 1995.

13. Oriá MOB, Alves MDS. Adolescente com papiloma vírus humano no contexto familiar. Rev Enferm UERJ 2004; 12 (1): 44-48.

14. Queiroz DT, Pessoa SMF, Sousa RA. Infecção pelo papiloma vírus humano: incertezas e desafios. Acta Paul Enferm 2005; 18 (2): 19096

15. Diógenes MAR. Estrutura, desenvolvimento e dinâmica da família da gestante com papiloma vírus humano [tese de doutorado]. Fortaleza (CE): Universidade Federal do Ceará; 2004. 